\title{
Munchausen Syndrome by Proxy Presented with Multiple Bone Fractures MF Ustundag ${ }^{1}$, G Ozpolat $^{1}$, H Ozcan $^{1}$, E Ozcan $^{1}$
}

\begin{abstract}
Munchausen Syndrome by Proxy is about the caregiver (perpetrator) who abuse and reveals signs of a disease of the victim because of her/his own psychological needs like attracting and getting attention. MSBP is a complicated child abusement form which may cause important physiological and psychological effects and has mortality risk in the long term period. In a study, $93 \%$ of the cases, perpetrator was found to be the mother, and according to the order of frequency, the other implementers were especially female babysitter and the father. Usually the symptoms dissappear during the mother's or the care giver's absence. In cases like our's, with continuously repeated and constant applications should be considered in the differential diagnosis of this condition. The more frequently reported findings are bleeding, apnea, nutritional problems, vomitting, diarrhea, convulsion, cyanosis, asthma, allergies, fever and pain. In studies conducted, the death rate is reported to be between $6-10 \%$ in the victims. Common opinion is that if no response is received from the practitioners in the treatment or if insufficient progress is shown (for ex. in 6 months period), victims should be taken from their environment and shouldn't be given back to their families. Here we are representing a case of MSBP who gives damage to her children by traumas like recurrent bone fractures and tissue damage, and as a result of a forensic notification, whose children are taken away and given to foster care.
\end{abstract}

Keywords: Bone fracture, child abuse, munchausen syndrome by proxy

Department of Psychiatry, Ataturk University Faculty of Medicine, Erzurum, Turkey.

Correspondence: Dr MF Ustundag,Department of Psychiatry,Faculty of Medicine, Ataturk University, Erzurum, Turkey. Fax: +904422361301, e-mail: mfustundag@gmail.com 


\section{INTRODUCTION}

Munchausen Syndrome by Proxy (MSBP) is about the caregiver (perpetrator) who abuse and reveals signs of a disease of the victim because of her/his own psychological needs like attracting and getting attention. MSBP may cause physiological and psychological effects and has mortality risk (1). Here we present a case of MSBP who gives damage to her children by producing traumas like recurrent bone fractures, and result of a forensic notification, whose children were taken away and given to foster care.

\section{CASE REPORT}

A 34-year-old woman with 6 children, brought her 5-year-old son to the emergency room complaint of right leg pain. She mentioned that her son fell of a broken ladder in their house. In his physical examination, there was sensibility in the right leg and the complaint of pain that occur with moving. In conventional radiography of bilateral lower extremity, a fracture in the right tibia was detected, the right leg was encased in plaster and discharged with follow-up recommendation. About two weeks later, she brought her 7-year-old son to the emergency room with difficulty in walking, bruises and scrubs in his legs. She again stated that he son fell down the stairs. As a result of the conducted analyses, no fractures were detected, though new bruises made the orthopedist suspicious. He was admitted to the orthopedic clinic and has been taken under treatment. Three months later, same woman brought her 12-year-old child to the emergency room with similar complaints. The orthopedist suspected of child abuse, requested psychiatric consultation and called the hospital police. In her psychiatric examination she was conscious, fully cooperated to time-place-person. Her affect was blunted and speech was in the form of question and answer. No perception and/or thought content 
abnormality was seen. Her intelligence quotient score was 83 implementing as dull intelligence level. The impression from the clinical observation was borderline mental capacity. In her anamnesis, she told that her husband was a long-distance driver, and because of that she has been spending most of the days of the year alone with her children. When the past hospital records about the family were investigated, it was found that there were many emergency appeals about her children. In the physical examinations of the children, there were scars and findings of older fractures from different time intervals in X-rays of the legs were seen. As her anamnesis was deepened, it was found that she had been creating bone fractures and bruises on her sons by using her husband's truck wedge. It was also learned that she has been giving information to her husband about the illnesses and hospitalization of the children and this made him come back home earlier than usual and spend more time together. This situation was reported to the forensic units; and children were taken away from their parents and placed in a state institution in where they will be taken care of.

\section{DISCUSSION}

Munchausen Syndrome by Proxy according to the types of other child abuse is quite common and the incidence studies in children under the age of 16 is $0.4 / 100000$ whereas under the age of 1 is $2-2.8 / 100000$ is found. However, the actual incidence is higher than this estimated amount (2-5). In a study, 93\% of the cases, perpetrator was found to be the mother similar with our case, and according to the order of frequency, the other implementers were babysitter and the father (5). In MSBP the symptoms, physical findings and laboratory results can be extraordinary, and usually inconsistent with the patient's situation and history. The relationship between the disease's clinical findings and prognosis can not be established. 
Patients usually do not respond to the treatment, or even if they do at the beginning, symptoms recrudescence afterwards (6). Usually the symptoms dissappear during the care giver's absence (7). In cases like our's, with continuously repeated and constant applications should be considered in the differential diagnosis of this condition. Due to the continuous applications to emergency service, diagnosis may go unnoticed. Most of the time doctors involuntarily get involved to this period with performing unnecessary diagnostic and interventional procedures or prescribing drugs that have a high potential for side effects. Victim's $75 \%$ of morbidity was found to be as a result of initiatives that are performed by doctors in the hospital (3). MSBP is a kind of a child abuse which has quite a high risk of morbidity and mortality. In studies conducted, the death rate is reported to be between 6-10\% in the victims. In addition to this, if the case is poisoned or suffocated, the death rate increases up to $33 \%(3,5)$. In this syndrome, it is hard to understand the underlying psychopathology of the practitioner. It should not be forgotten that, there is no diagnostic test or psychological profile that excludes or supports the diagnosis of the MSBP. In MSBP narsisistic fragility and borderline personality traits are frequent; also passive-dependent, hysterical personality traits, different sadomasochistic behaviors, mild or borderline mental retardation, compliance issues and depression have been found (8). In our case, the patient was thought to have borderline mental capacity. This situation may have influenced the mother's executive functions negatively so that she could not find an alternative solution to absence of her husband in order to spend more time with him.

It is known that MSBP has a high relapse risk (9). In our case, a rare type of MSBP is studied which occured with repetitive bone fractures in multiple family members. It has been noticed that the mother was trying to draw attention by creating these bone fractures and intended to spend more time with her husband. Another MSBP case diagnosed on suspicion 
after eleven months of having repetitive humerus, femur and tibia fractures and skin lesions in a 3-year-old victim. The mother created disease symptoms on the child in order to maintain her own psychological needs and tried to organize her husband and spend more time with him (10). There are limited number of studies about long-term follow-ups of the victims who were exposed to childhood abuse. In these studies, it is reported that starting from childhood and continuing in adulthood, victims may develop problems like insecurity, being opposed and oppositional defiant disorder, post-traumatic disorder, attention disorders, attachment and social relationship problems, avoiding medical treatment and low self-esteem. What is more, it is found that some of the victims developed "Munchausen Syndrome" in adolescence and young adulthood $(1,11)$. In our case, information on the progress of the victims could not be obtained because they were placed in foster care. Making a diagnosis is usually hard; if any case is considered to be MSBP, should be approached in a suspicious manner to each case. It is important to remember that the first condition of the diagnosis is to be suspicious; if there are any diagnosis of suspected MSBP cases, a retrospective review of them and their siblings should be performed.

As we did in our case, investigating the hospital records of the patient's siblings is important for the diagnosis. A collaborative work of a multidisciplinary team provide guidance for the diagnosis of MSBP. Priority should be given to victim's safety while collecting the necessary evidence for diagnosis, and child's life should not be at more risk. Common opinion is that if no response is received from the practitioners in the treatment or if insufficient progress is shown (for example in 6 months period), victims should be taken from their environment and should not be given back to their families. Due to the high risk of recurrence in the children who are given back to their families, close monitoring and followups are recommended $(3,9)$. Children in our case were taken from their families and have 
been taken under state protection. We can not give further information about the current status because we could not follow the family further. 


\section{REFERENCES}

1. Sharif I. Munchausen syndrome by proxy. Pediatrics in review/American Academy of Pediatrics. 2004; 25: 215-6.

2. McGovern M, Smith M. Causes of apparent life threatening events in infants: a systematic review. Arch Dis Child. 2004; 89: 1043-8.

3. Galvin HK, Newton AW, Vandeven AM. Update on Munchausen syndrome by proxy. Curr Opin Pediatr. 2005; 17: 252-7.

4. Hymel KP and the Committe on Child Abuse and Neglect. Distinguishing sudden infant death syndrome from child abuse fatalities. Pediatrics. 2001; 107: 437-41.

5. Terry L. Fabricated or induced illness in children: Nurses focus on protecting children but they also need support and protection from harm during and after an investigation, as Louise Terry explains. Paediatric Care. 2004; 16:14-8.

6. Foto-Özdemir D, Yalçın SS, Zeki A, Yurdakök K, Özusta Ş, Köse A et al. Munchausen syndrome by proxy presented as recurrent respiratory arrest and thigh abscess: A case study and overview. Turk J Pediatr. 2013; 55: 437-43.

7. Squires JE, Squires Jr RH. Munchausen syndrome by proxy: ongoing clinical challenges. J Pediatr Gastr Nutr. 2010; 51: 248-53.

8. Bouden A, Krebs M, Loo H, Olie J. [Munchhausen syndrome by proxy: a challenge for medicine]. Presse medicale (Paris, France: 1983). 1996; 25: 567-9.

9. Rosenberg DA. Web of deceit: a literature review of Munchausen syndrome by proxy. Child Abuse Neglect. 1987; 11: 547-63.

10. Sugandhan S, Gupta S, Khandpur S, Khnna N, Mehta M, Inna MS P. Munchausen syndrome by proxy' presenting as battered child syndrome: a report of two cases. Int J Dermatol. 2010; 49: 679-83. 
11. Bools C, Neale B, Meadow S. Follow up of victims of fabricated illness (Munchausen syndrome by proxy). Arch Dis Child. 1993; 69: 625-30. 